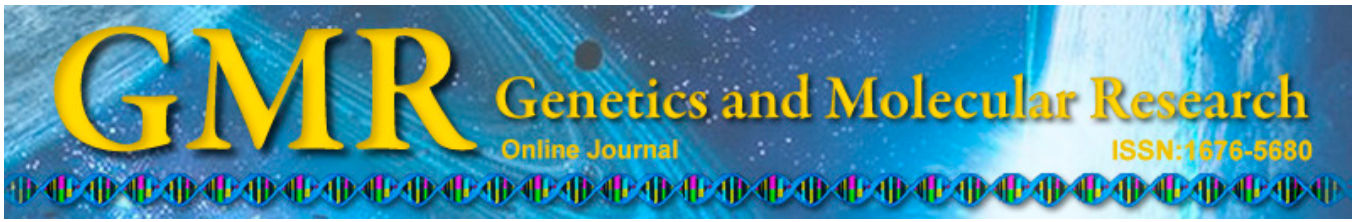

\title{
Taxonomic status of Pinus henryi using multiplexed microsatellite markers
}

\author{
Q. Xie, Z.-H. Liu and Z.-Q. Li \\ College of Forestry, Northwest A\&F University, Yangling, China \\ Corresponding author: Z.-Q. Li \\ E-mail: lizhouqi@nwsuaf.edu.cn
}

Genet. Mol. Res. 14 (2): 4549-4556 (2015)

Received July 11, 2014

Accepted November 5, 2014

Published May 4, 2015

DOI http://dx.doi.org/10.4238/2015.May.4.13

\begin{abstract}
The taxonomic status of Pinus henryi, a rare species endemic to China, is still ambiguous. In this study, the genetic relationships among $P$. henryi and its congeners ( $P$. tabulaeformis, P. tabulaeformis var. mukdensis, and P. massoniana) were revealed using multiplexed microsatellite markers, including chloroplast microsatellites, nuclear microsatellites, and expressed sequence tag microsatellites. The results refute the hypothesis that $P$. henryi is a subspecies of $P$. tabulaeformis or $P$. massoniana and support the suggestion that it may be a distinct species closely related to $P$. tabulaeformis.
\end{abstract}

Key words: Pinus henryi; SSR markers; Narrow endemic; Taxonomic status 


\section{INTRODUCTION}

Pinus henryi, first described in 1902 by Masters, is a rare and endemic pine in China. There is controversy regarding the taxonomic position of $P$. henryi, and it has been a matter of debate from the 19th century to the present. $P$. henryi was initially synonymized with $P$. tabulaeformis by Cheng (1930), then treated as a variety of $P$. massoniana (Wu, 1956; Kuan, 1983), and finally it has been treated as a variety (Guan, 1982) or subspecies (Businsky, 1999) of P. tabulaeformis. However, the taxon has previously been treated as a distinct species (Zheng and Fu, 1978) and is still accepted as such in some studies (Niu, 1990; Zhang et al., 1995; Zhang, 1996; Zhao and Liu, 2010).

To settle the taxonomic status of $P$. henryi, extensive research has been carried out over the last 20 years using traditional morphological characters ( $\mathrm{Li}$ and Xu, 1989; An and Zhao, 1992; Zhao and Liu, 2010). Based on these studies, $P$. henryi was treated as a distinct species. However, identification of closely related species based on morphological analysis may be distorted by a high level of homoplasy (Nyffeler et al., 2005). Recently, developed molecular methods offer significant opportunities to explore species delimitation (Bodo Slota and Porter, 2006; Liu et al., 2011; Yan et al., 2014).

Microsatellite markers (simple sequence repeats; SSR) are highly polymorphic, informative, co-dominant, technically simple, and reproducible (Gupta et al., 1996). Microsatellites have been successfully used for cultivar identification (Cardoso et al., 2014), hybrid species discrimination (Dong et al., 2011), and genetic map construction (Wang et al., 2014), as well as intra- and interspecies genetic diversity and relationship determination in closely related taxa (Guo and Luo, 2011; Qin et al., 2013).

In this study, we applied multiplexed microsatellite markers (including chloroplast microsatellites, nuclear microsatellites, and expressed sequence tag microsatellites) to elucidate the genetic relationships among $P$. henryi and its congeners: $P$. tabulaeformis, $P$. tabulaeformis var. mukdensis, and P. massoniana. All 4 pines are geographically and phylogenetically closer to each other than to any other Chinese pines (Wang et al., 1999). Our aims were to verify the reliability of previous systematic hypotheses, in particular whether $P$. henryi should be classified as a subspecies of P. tabulaeformis or P. massoniana.

\section{MATERIAL AND METHODS}

\section{Plant material}

Four taxa of Pinus were analyzed in this study: P. henryi, P. tabulaeformis, P. tabulaeformis var. mukdensis (the variety of $P$. tabulaeformis), and P. massoniana. The geographic location of taxa and the number of accessions sampled are shown in Table 1. Fresh needles were sampled from individual adult trees from each population. Distances between sampled trees ranged from 50-100 m depending on the population size, to ensure that the sample trees were representative of their populations. To avoid degradation of plant tissues, all samples were labeled and stored in sealed bags with silica gel as described by Sytsma et al. (1993) until DNA extraction. 
Table 1. Locations of the sampled Pinus taxa and sample number (N).

\begin{tabular}{lcllcr}
\hline Taxa & Code & Locality & N & Latitude $\left({ }^{\circ} \mathrm{N}\right) /$ Longitude $\left({ }^{\circ} \mathrm{E}\right)$ & Elevation $(\mathrm{m})$ \\
\hline P. henryi & $\mathrm{B}$ & Nanzheng, Shaaxi & 30 & $32.857 / 106.586$ & 1254 \\
P. tabulaeformis & $\mathrm{Y}$ & Huanglong, Shaanxi & 30 & $35.632 / 109.772$ & 1127 \\
P. tabulaeformis var. mukdensis & $\mathrm{H}$ & Anshan, Liaoning & 30 & $40.960 / 123.147$ & 294 \\
P. massoniana & $\mathrm{M}$ & Yangxian, Shaanxi & 30 & $33.326 / 107.624$ & 722 \\
\hline
\end{tabular}

\section{DNA extraction and SSR-polymerase chain reactions (PCR) amplification}

Total genomic DNA was extracted from silica gel-dried needles of each plant using the DNAsecure Plant kit (TIANGEN Biotech Co., Ltd., Beijing, China). Quality of the total DNA was verified by gel electrophoresis (1\% agarose gel) and quantified using a BioPhotometer plus (Eppendorf, Hamburg, Germany). DNA samples were stored at $-20^{\circ} \mathrm{C}$ until SSR amplification.

Six CpSSR primers (Pt48210, Pt110048, Pt41093, Pt30204, Pt1254, and Pt26081), 4 NSSR primers (B4D05, PtTX3107, NZPR114, and NZPR554), and 3 EST-SSR primers (Ptctg5167, Ptctg64, and RPtest5) were selected based on previous reports (Vendramin et al., 1996; Liewlaksaneeyanawin et al., 2004; Marum et al., 2009) (Table 2). PCRs were performed using $50 \mathrm{ng}$ DNA in a volume of $20 \mu \mathrm{L}$ containing $1 \mathrm{X}$ PCR buffer, $0.2 \mathrm{mM}$ dNTPs, $0.2 \mathrm{mM}$ $\mathrm{Mg}^{2+}, 0.2 \mathrm{mM}$ of each primer pair, and $1 \mathrm{U}$ Taq DNA polymerase. The cycle program included an initial 5 min denaturation at $94^{\circ} \mathrm{C}$, followed by 35 cycles of $1 \mathrm{~min}$ at $94^{\circ} \mathrm{C}, 1 \mathrm{~min}$ at $58^{\circ} \mathrm{C}$, and $1 \mathrm{~min}$ at $72^{\circ} \mathrm{C}$, with a 10 -min final extension at $72^{\circ} \mathrm{C}$.

The amplification products were separated by $6 \%$ polyacrylamide gel electrophoresis and visualized using a simplified silver-staining method previously described by Xu et al. (2002).

\section{Data analysis}

Only clear, well-defined, and reproducible bands were recorded, and SSR loci were scored individually. For the statistical analysis, the patterns at all SSR loci were scored 1 for the presence of a band and 0 for the absence of a band in a binary data matrix for further analysis. Percentage of polymorphic bands (PPB) were calculated according to Smith et al. (1997). The binary matrix was transformed into a Nei and Li genetic distance matrix using FreeTree (Hampl et al., 2001). The phenograms were constructed using the neighbor-joining (NJ) method in the MEGA 4.0 software (Tamura et al., 2007). A principal coordinate analysis (PCoA) was performed based on the variance covariance matrix calculated from marker data using the program GenAlEx v6.5 (Peakall and Smouse, 2012). Bayesian analysis of SSR population structure was performed on the entire data set using the program STRUCTURE 2.3.2 (Pritchard et al., 2000) to detect population structure and estimate the number of populations $(K)$ in a sample as well as to assign individuals to 1 or more of these populations $(K)$. The number of genetically distinct clusters $(K)$ was set to vary from 1-4. The model was run for 10 independent simulations for each $K$, using a burn-in length of 50,000 and a run length of 100,000 iterations. The most likely number of clusters was estimated according to the model value $(\Delta K)$ based on the second-order rate of change, with respect to $K$, of the likelihood function, following the procedure described by Evanno et al. (2005).

\section{RESULTS}

Amplification was successful for all 13 SSR markers. The total number of bands scored 
per primer combination ranged from 3 to 15 , with an average of 6.4 bands per primer set. The PPB for the 18 primer combinations were all $100 \%$, confirming their utility to show differences between the samples analyzed in this study (Table 2).

Table 2. Primer sequences and characteristics of microsatellite loci in the Pinus taxa.

\begin{tabular}{|c|c|c|c|c|}
\hline Primer & Primer sequence $\left(5^{\prime}-3^{\prime}\right)$ & Allele size (bp) & Number of alleles & PPB \\
\hline Pt48210 & $\begin{array}{l}\text { F-CGAGATTGATCCGATACCAG } \\
\text { R-GAGAGAACTCTCGAATTTTTCG }\end{array}$ & $89-121$ & 6 & 100 \\
\hline Pt110048 & $\begin{array}{l}\text { F-TAAGGGGACTAGAGCAGGCTA } \\
\text { R-TTCGATATTGAACCTTGGACA }\end{array}$ & $67-138$ & 6 & 100 \\
\hline Pt41093 & $\begin{array}{l}\text { F-TCCCGAAAATACTAAAAAAGCA } \\
\text { R-CTCATTGTTGAACTCATCGAGA }\end{array}$ & $78-154$ & 3 & 100 \\
\hline Pt30204 & $\begin{array}{l}\text { F-TCATAGCGGAAGATCCTCTTT } \\
\text { R-CGGATTGATCCTAACCATACC }\end{array}$ & $112-145$ & 6 & 100 \\
\hline Pt1254 & $\begin{array}{l}\text { F-CAATTGGAATGAGAACAGATAGG } \\
\text { R-TGCGTTGCACTTCGTTATAG }\end{array}$ & $72-174$ & 15 & 100 \\
\hline Pt26081 & $\begin{array}{l}\text { F-CCCGTATCCAGATATACTTCCA } \\
\text { R-TGGTTTGATTCATTCGTTCAT }\end{array}$ & $89-112$ & 4 & 100 \\
\hline B4D05 & $\begin{array}{l}\text { F-TTTCGGCATCACAACAGC } \\
\text { R-GTTTGGAAGCTGGAAGTTGG }\end{array}$ & $218-234$ & 3 & 100 \\
\hline PtTX3107 & $\begin{array}{l}\text { F-AAACAAGCCCACATCGTCAATC } \\
\text { R-TCCCCTGGATCTGAGGA }\end{array}$ & $150-164$ & 8 & 100 \\
\hline NZPR114 & $\begin{array}{l}\text { F-AAGATGACCCACATGAAGTTTGG } \\
\text { R-GGAGCTTTATAACATATCTCGATGC }\end{array}$ & $179-187$ & 4 & 100 \\
\hline NZPR554 & $\begin{array}{l}\text { F-GCGATGTGCAACCCTTGATA } \\
\text { R-TGCTATTCCGTCAAAAACCC }\end{array}$ & $246-252$ & 9 & 100 \\
\hline Ptctg5167 & $\begin{array}{l}\text { F-TGCAGAGAGATTCGATGGG } \\
\text { R-ATTTTGGTTTGTTTGCTGGC }\end{array}$ & $293-358$ & 10 & 100 \\
\hline Ptctg64 & $\begin{array}{l}\text { F-GGAAGCTGTTACAAGTGCGG } \\
\text { R-ATCGAGAAAGAGAGGAAGGG }\end{array}$ & $236-284$ & 4 & 100 \\
\hline RPtest5 & $\begin{array}{l}\text { F-ACAACAATAATAACGGGGGC } \\
\text { R-ACGCTTTAGATCCTCCTGCA }\end{array}$ & $197-226$ & 6 & 100 \\
\hline
\end{tabular}

$\mathrm{PPB}=$ percentage of polymorphic bands.

To assess the taxonomic status of $P$. henryi, NJ cluster analysis was performed for all individuals of the Pinus taxa (Figure 1). Samples of P. tabulaeformis $(\mathrm{Y})$ and P. tabulaeformis var. mukdensis $(\mathrm{H})$ clustered together, while samples of $P$. henryi and $P$. massoniana clustered within 2 well-differentiated groups in the NJ dendrogram (Figure 1). This confirmed the grouping of individuals within their own taxonomic range. P. massoniana (M) appeared to be the most genetically differentiated. The genetic relationship between $P$. henryi and $P$. tabulaeformis was closer than that between $P$. henryi and $P$. massoniana.

PCoA was performed to provide spatial representation of the relative genetic distances among individuals and to determine the consistency of differentiation among taxa defined by the cluster analysis. The first 2 principal components explained 44.70 and $17.20 \%$ of the total variation, respectively, while $74.43 \%$ was explained by the first 3 components (Figure 2). The first principal coordinate separated most individuals of $P$. henryi (B) from the individuals of the other 3 taxa. The second principal coordinate separated most individuals of $P$. massoniana (M) from the individuals of the other 3 taxa. The results of the PCoA indicated that $P$. henryi might be a distinct species closely related to $P$. tabulaeformis.

In the SSR admixture analysis using STRUCTURE (Figure 3), the highest likelihood of the data was obtained when samples were clustered into 3 groups $(K=3)$. For the 4 Pinus taxa dataset, the 3 clusters corresponded to $P$. henryi (B, green cluster), the combination of $P$. tabulaeformis $(\mathrm{Y})$, and P. tabulaeformis var. mukdensis $(\mathrm{H}$, red cluster), and to P. massoniana (M, blue cluster), further indicating that these results agreed with the PCoA and the NJ cluster results. 


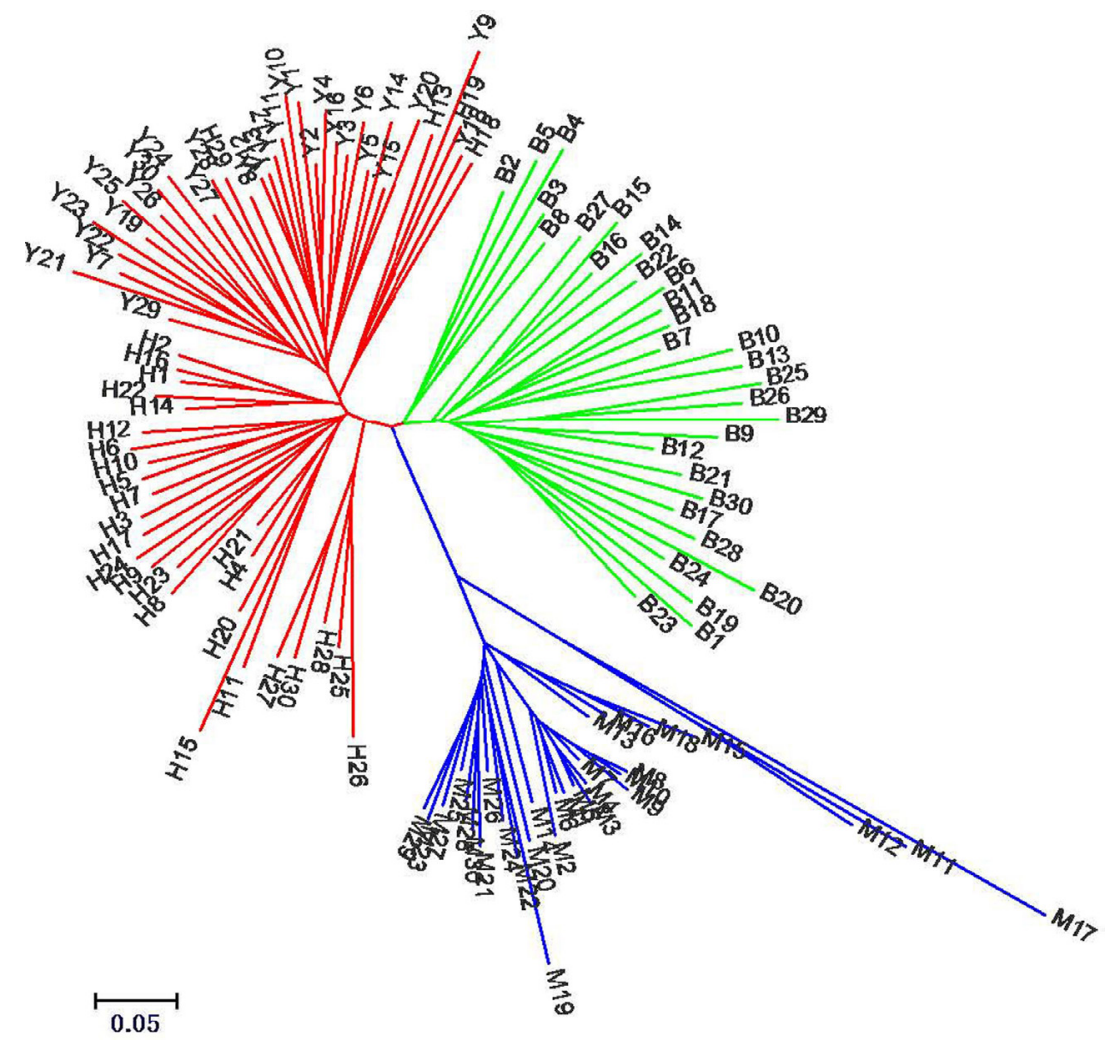

Figure 1. Dendrogram for all individuals of the Pinus taxa using the neighbor-joining method.

\section{Principal Coordinates (PCoA)}

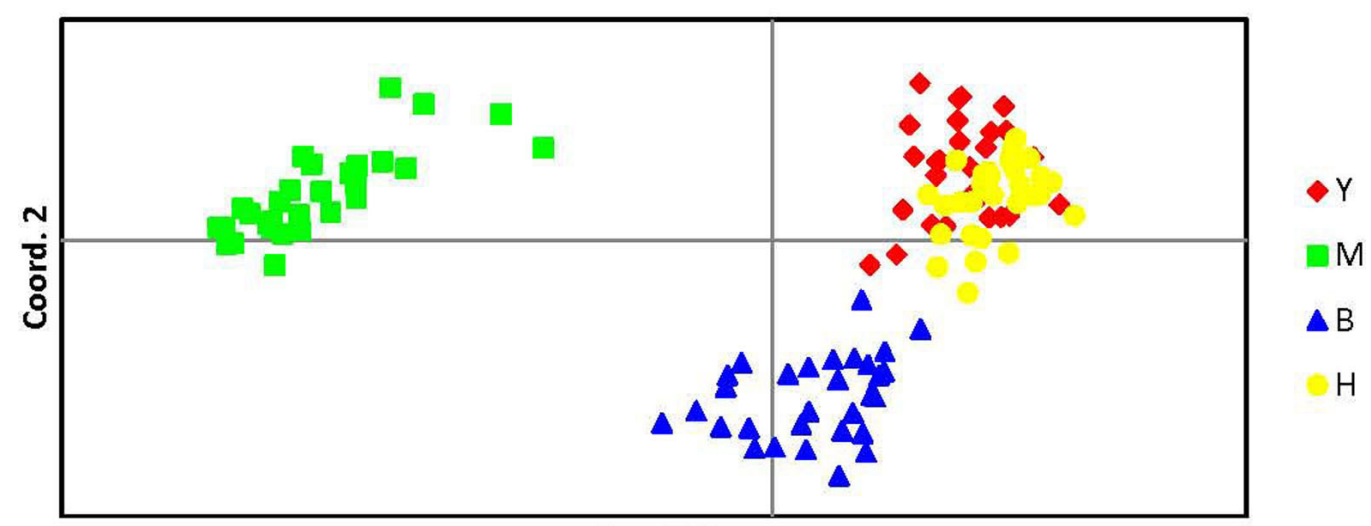

\section{Coord. 1}

Figure 2. Two-dimensional plot of the principal coordinate analysis of SSR data showing the clustering of populations of Pinus taxa. The first and second principal coordinates account for 44.70 and $17.20 \%$ of the total variation, respectively. 


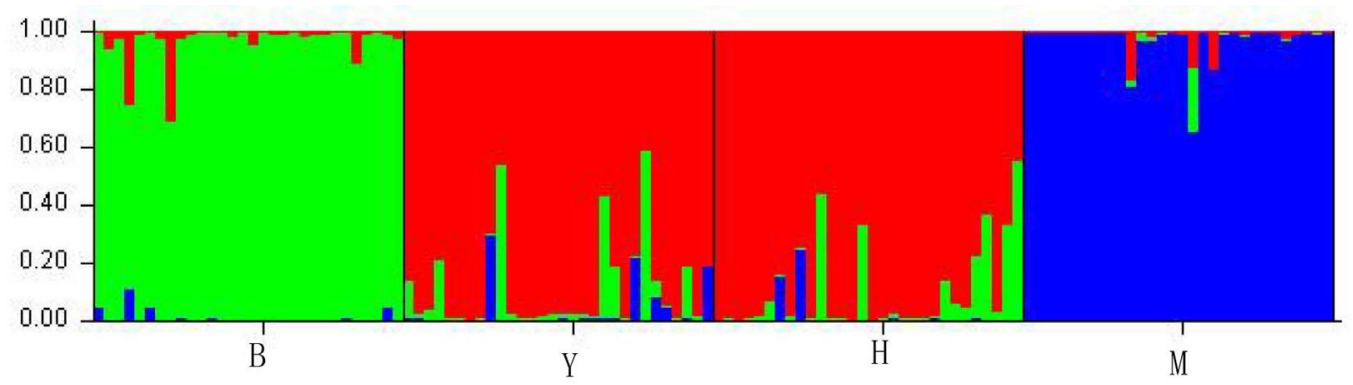

Figure 3. Genetic relationships among the Pinus taxa estimated using STRUCTURE based on SSR data. The model with $K=3$ showed the highest $K$ value.

\section{DISCUSSION}

The controversy over the taxonomic status of the 4 pines in this study mainly lay in the relationship between $P$. henryi and $P$. tabulaeformis. These two species have a similar morphology and adjacent distributions ( $\mathrm{Li}$ and $\mathrm{Xu}, 1989$ ). However, the NJ dendrogram (Figure 1), the PCoA diagram (Figure 2), and the STRUCTURE plot (Figure 3) exhibited similar patterns, revealing that $P$. henryi, $P$. tabulaeformis and $P$. tabulaeformis var. mukdensis, and $P$. massoniana were distinctly differentiated, suggesting they have different genetic backgrounds. These results indicate that $P$. henryi should be a distinct species rather than a subspecies of $P$. tabulaeformis or P. massoniana.

In addition, our results are strongly supported by morphological and biochemical studies. Compared to $P$. tabulaeformis, $P$. henryi has a wider stem taper, smaller seeds $(6.37$ vs $7.02 \mathrm{~mm})$ and cones $(4.44$ vs $5.58 \mathrm{~cm})$, and shorter $(10.31$ vs $11.81 \mathrm{~cm})$, narrower $(1.21 v s$ $1.24 \mathrm{~cm}$ ), and thinner (0.70 vs $0.79 \mathrm{~mm}$ ) needles (Mao and Liu, 1989; Li and Xu, 1989). Furthermore, $P$. henryi exhibits a diagnostic karyotype with diacritic satellite positions on its chromosomes (Zhang, 1990). Wood anatomical characteristics (e.g., number of secretory cells in the resin duct, thickness of the inner wall of ray tracheids, the number of uniseriate wing cells in fusiform ray; An and Zhao, 1992), and physio-biochemical traits (chlorophyll and nuclear acid content, peroxidase isozymes; Zhang et al., 1995) have congruously demonstrated the differences between $P$. henryi and $P$. tabulaeformis. Furthermore, these species have allopatric distributions with their morphologic-geographic division running in the Daba Mountains (Li and $\mathrm{Xu}, 1989)$. P. tabulaeformis is distributed on the northern slope of the Daba Mountains, while $P$. henryi is found on the southern slope.

Therefore, we conclude that all evidence from geographical, morphological, biochemical, karyotype, and genetic data refute the subspecies hypothesis and indicate that Pinus henryi may be a distinct species closely related to P. tabulaeformis.

\section{ACKNOWLEDGMENTS}

Research supported by the National Natural Science Foundation of China (Grant \#30972382).

\section{REFERENCES}

An PJ and Zhao L (1992). Identification and wood anatomical features of Pinus henryi Mast. J. Northwest For. Univ. 7: 1-6. 
Bodo Slota TA and Porter DM (2006). Genetic variation within and between Iliamna corei and I. remota (Malvaceae): implications for species delimitation. Bot. J. Linn. Soc. 151: 345-354.

Businsky R (1999). Taxonomic revision of Eurasian pines (genus Pinus L.): survey of species and infraspecific taxa according to latest knowledge. Acta Pruhon 68: 7-86.

Cardoso PCB, Brondani C, Menezes IPP, Valdisser PA, et al. (2014). Discrimination of common bean cultivars using multiplexed microsatellite markers. Genet. Mol. Res. 13: 1964-1978.

Cheng WC (1930). A study of the Chinese pines. Contrib. Biol. Lab. Sci. Soc. China Bot. Ser. 6: 5-21.

Dong WJ, Wu MD, Lin Y, Zhou MB, et al. (2011). Evaluation of 15 caespitose bamboo EST-SSR markers for crossspecies/genera transferability and ability to identify interspecies hybrids. Plant Breed. 130: 596-600.

Evanno G, Regnaut S and Goudet J (2005). Detecting the number of clusters of individuals using the software STRUCTURE: a simulation study. Mol. Ecol. 14: 2611-2620.

Guan ZT (1982). Geography of Pinaceae and Taxodiaceae in Sichuan Chengdu. People Publishing House, Chengdu.

Guo DL and Luo ZR (2011). Genetic relationships of the Japanese persimmon Diospyros kaki (Ebenaceae) and related species revealed by SSR analysis. Genet. Mol. Res. 10: 1060-1068.

Gupta PK, Balyan HS, Sharma PC and Ramesh B (1996). Microsatellites in plants: a new class of molecular markers. Curr. Sci. 70: 45-54.

Hampl V, Pavlícek A and Flegr J (2001). Construction and bootstrap analysis of DNA fingerprinting-based phylogenetic trees with the freeware program FreeTree: application to trichomonad parasites. Int. J. Syst. Evol. Microbiol. 51: 731-735.

Kuan CT (1983). Flora Sichuanica 2 (Gymnospermae). Sichuan Sci. Technol. Press, Chengdu.

Li CX and Xu HC (1989). A numerical analysis on the dividing line of geographic distribution and taxonomy relation between Pinus henryi Mast. and P. tabulaeformis Carr. Sci. Silvae Sin. 25: 14-21.

Liewlaksaneeyanawin C, Ritland CE, El-Kassaby YA and Ritland K (2004). Single-copy, species-transferable microsatellite markers developed from loblolly pine ESTs. Theor. Appl. Genet. 109: 361-369.

Liu L, Zhao B, Tan DY and Wang JB (2011). Phylogenetic relationships of Brassicaceae in China: insights from a noncoding chloroplast, mitochondrial, and nuclear DNA data set. Biochem. Syst. Ecol. 39: 600-608.

Mao S and Liu Y (1989). Stem anatomy of Pinus tabulaeformis and Pinus henryi. J. North For. College 4: 94-99.

Marum L, Rocheta M, Maroco J, Oliveira MM, et al. (2009). Analysis of genetic stability at SSR loci during somatic embryogenesis in maritime pine (Pinus pinaster). Plant Cell Rep. 28: 673-682.

Niu CS (1990). Woody flora of Shannxi. Chinese Forestry Publishing House, Beijing.

Nyffeler R, Bayer C, Alverson WS, Yen A, et al. (2005). Phylogenetic analysis of the Malvadendrina clade (Malvaceae s.1.) based on plastid DNA sequences. Org. Divers. Evol. 5: 109-123.

Peakall R and Smouse PE (2012). GenAlEx 6.5: genetic analysis in Excel. Population genetic software for teaching and research-an update. Bioinformatics 28: 2537-2539.

Pritchard JK, Stephens M and Donnelly P (2000). Inference of population structure using multilocus genotype data. Genetics 155: 945-959.

Qin Y, Shi G and Sun Y (2013). Evaluation of genetic diversity in Pampus argenteus using SSR markers. Genet. Mol. Res. 12: 5833-5841.

Smith JSC, Chin ECL, Shu H, Smith OS, et al. (1997). An evaluation of the utility of SSR loci as molecular markers in maize (Zea mays L.): comparisons with data from RFLPs and pedigree. Theor. Appl. Genet. 95: 163-173.

Sytsma KJ, Givnish TJ, Smith JF and Hahn WJ (1993). Collection and storage of land plant samples for macromolecular comparisons. Methods Enzymol. 224: 23-37.

Tamura K, Dudley J, Nei M and Kumar S (2007). MEGA 4: Molecular evolutionary genetics analysis (MEGA) software version 4.0. Mol. Biol. Evol. 24: 1596-1599.

Vendramin GG, Lelli L, Rossi P and Morgante M (1996). A set of primers for the amplification of 20 chloroplast microsatellites in Pinaceae. Mol. Ecol. 5: 595-598.

Wang HX, Walla JA, Magnusson VA, Zhong SB, et al. (2014). Construction of genetic linkage maps and QTL mapping for X-disease resistance in tetraploid chokecherry (Prunus virginiana L.) using SSR and AFLP markers. Mol. Breeding 34: 143-157.

Wang XR, Tsumura Y, Yoshimaru H, Nagasaka K, et al. (1999). Phylogenetic relationships of Eurasian pines (Pinus, Pinaceae) based on chloroplast rbcL, MATK, RPL20-RPS18 spacer and TRNV intron sequences. Am. J. Bot. 86: 1742-1753.

Wu ZL (1956). The Classification and distribution of Pinaceae in China. Acta Phytotaxon. Sin. 5: 153-154.

Xu SB, Tao YF, Yang ZQ and Chu JY (2002). A simple and rapid method used for silver staining and gel preservation. Hereditas 24: 335-336.

Yan QQ, Li Y, Sun XQ, Guo JL, et al. (2014). Isolation and characterization of polymorphic microsatellite loci from aerial yam (Dioscorea bulbifera L.). Genet. Mol. Res. 13: 1514-1517.

Zhang CX (1996). Advances in research of Pinus henryi. Shaanxi For. Sci. Technol. 1: 11-14. 
Zhang CX, Zhang FQ and Qiu MG (1995). A study on the taxonomy position of Pinus henryi in Nanzheng of Shaanxi. $J$. Northwest For. Coll. 10: 38-42.

Zhang FQ (1990). Original breeding material of Pinus henryi Mast. J. Northwest For. Univ. 5: 64-79.

Zhao Y and Liu ZL (2010). Numerical analysis to anatomical structures of needles between five species of pines. $J$. Northwest For. Univ. 25: 19-24.

Zheng WJ and Fu LG (1978). Flora Reipublicae Popularis Sinicae. Science Press, Beijing. 